
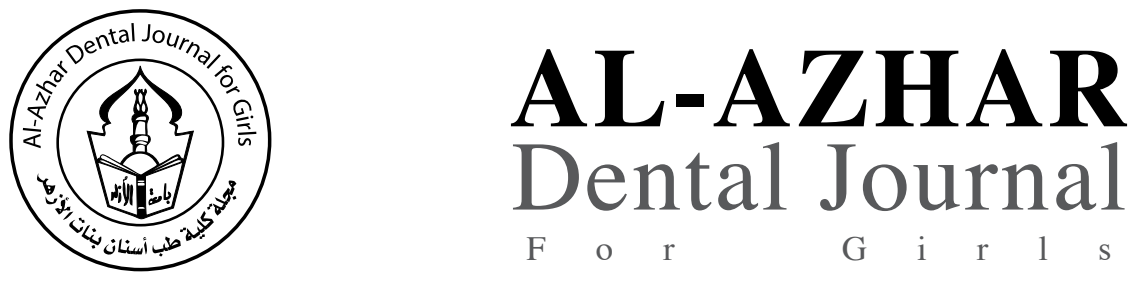

The Official Publication of The Faculty of Dental Medicine For Girls, Al-Azhar University Cairo, Egypt.

ADJ-for Grils, Vol. 3, No. 3, July (2016) — PP. 215:221

\title{
A Clinical and Laboratory Evaluation of Different Remineralizing Agents Used for Treatment of Carious Posterior Teeth
}

\author{
Eman Abdel-Raouf Mohamed $^{(1)}$, Eatimad Ahmed Shoreibah ${ }^{(2)}$, Eman Sayed Elmasry ${ }^{(3)}$, \\ Maha Ahmed Niazy ${ }^{(4)}$ and Mohamed Hassan Mostafa ${ }^{(5)}$
}

Codex : 08/1607

dentaljournal.forgirls@yahoo.com

\begin{abstract}
Objective: The purpose of this study is to 1) evaluate clinically and radiographically the carious dentin treated with Ozone, Casein Phosphopeptide - Amorphous Calcium Phosphate (Tooth Mousse) mixed with Glass Ionomer and Glass Ionomer Cement only in primary molars of $4-8$ years old children (In vivo study), and 2) Compare the micro hardness of carious dentin treated with Ozone, Casein Phosphopeptide - Amorphous Calcium Phosphate (Tooth Mousse) mixed with Glass Ionomer and Glass Ionomer Cement only in extracted primary molars (In vitro study). Design: Forty five primary molars with proximal caries in children, ranging in their age from 4-8 years old. They were equally divided into three groups (15 each) according to the materials were used for restoration. The first group was restored with glass ionomer cement, the second group was restored with Casein Phosphopeptide - Amorphous Calcium Phosphate (CPP-ACP ) incorporated with glass ionomer cement, and the third group was pretreated with ozonized olive oil then restored with glass ionomer cement. Also this study was carried out on forty five freshly extracted carious primary molars, which divided equally into three groups and restored as mentioned before in clinical cases and examined for microhardness assessment. Results: the greatest value of mean radiodensity was recorded in Tooth Mousse group followed by Glass ionomer group then Ozone group. However there was no statistically significant difference between the three groups. Conclusion: Casein phosphopeptide - Amorphous Calcium Phosphate (Tooth Mousse) mixed with Glass ionomer cement as well as glass ionomer alone seemed to be successful as a remineralizing agent in primary molars.
\end{abstract}

1. Assistant Lecturer, Pediatric Dentistry and Public Health, Faculty of Dental Medicine for Girls, Al- Azhar University.

2. Professor of Oral Medicine and Periodontology, and Former Dean, Faculty of Dental Medicine for Girls, Al-Azhar University.

3. Professor of Pediatric Dentistry and Public Health, Faculty of Oral and Dental Medicine, Cairo University.

4. Professor of Operative Dentistry, and Former Vice Dean, Faculty of Dental Medicine for Girls, Al-Azhar University.

5. Associate Professor of Pediatric Dentistry and Public Health, Faculty of Dental Medicine for Girls, Al- Azhar University. 


\section{INTRODUCTION}

Dental Caries is a multifactorial disease caused by the interaction of dietary sugars, dental biofilm and host's dental tissue within the oral environment ${ }^{(1)}$. It is the cumulative results of consecutive cycles of demineralization and remineralization at the interface between the biofilm and the tooth surface. Oral bacteria excrete acid after consuming sugar and plaque $\mathrm{pH}$ falls to 5.5, leading to demineralization ${ }^{(2)}$.

Thus, conversely remineralization occurs when $\mathrm{pH}$ rises and there is deposition of calcium, phosphate and fluoride ions in the form of fluorapatite which are more resistant to crystals dissolution ${ }^{(3)}$.

Remineralization technology based on phosphopeptide from milk protein casein has been developed. The casein phosphopeptides (CPP) contain multiphosphoseryl sequences with the ability to stabilize calcium phosphate in nanocomplexes in solutions like amorphous calcium phosphate (ACP). The CPP-ACP also acts as reservoir of bio-available calcium and phosphate, and maintains the solution supersaturated, thus facilitating remineralization ${ }^{(4)}$.

During the last years, ozone gas therapy has been suggested as an alternative non-invasive treatment aiming to reduce the levels of caries-associated microorganisms. This therapy may be an alternative or complementary treatment strategy in dentistry. Ozone is an energy-rich and highly unstable form of oxygen. It is a strong and fast oxidizer of cell walls and cytoplasmic membranes of bacteria and is considered to be one of the best bactericidal, antiviral and antifungal agents ${ }^{(5)}$.

Glass ionomer cement (GIC) is a material used in order to prevent demineralization, enhance remineralization of enamel and dentin and inhibit bacterial growth that causes dental caries, because of its caries-protective effect through the release of fluoride ${ }^{(6)}$.

Therefore this study was conducted to evaluate the remineralizing capacity of glass ionomer cement, Casein Phosphopeptide Amorphous Calcium
Phosphate (CPP-ACP) incorporated into glass ionomer cement and ozone on carious dentin of deciduous molars.

\section{MATERIALS AND METHODS}

Forty five primary molars with proximal caries in children, ranging in their age from 4- 8 years old were selected from outpatient clinic of the Pedodontic Department, Faculty of Dental Medicine, Al-Azhar University. All parents were asked to sign a written consent. A detailed medical history was taken from the parents; a periapical radiograph of the selected tooth was taken prior treatment. Teeth were equally divided into three groups (15 each) according to the materials were used for restoration. The first group was restored with glass ionomer cement, the second group was restored with Casein Phosphopeptide - Amorphous Calcium Phosphate (CPP-ACP) incorporated with glass ionomer cement, and the third group was pretreated with ozonized olive oil then restored with glass ionomer cement. Also this study was carried out on forty five freshly extracted carious primary molars, which divided equally into three groups and restored as mentioned before in clinical cases and examined for microhardness assessment.

\section{Observation period}

The teeth were reviewed after 3, 6, 9, 12 and 18 months. At each review appointment, patients were clinically assessed for: pain, tenderness on percussion, mobility and pulp status. Radiographs were taken prior to treatment (baseline), then after 3 months, 6 months, 9 months, 12 months and 18 months. These were compared to assess whether any root resorption, widening of the periodontal ligament space, periapical radiolucency, progression or regression of carious lesions had developed following treatment.

\section{Clinical evaluation}

At each assessment appointment, the presence or absence of the following was recorded: pain, tenderness to percussion, mobility and pulp 
vitality. All recorded data for total follow up period were recorded in the recall sheet and saved on the computer.

\section{Radiographic evaluation}

Standardized reproducible periapical radiographs for each treated tooth were evaluated preoperatively then at $3,6,9,12 \& 18$ months after treatment. An indirect digital image radiographic system; the DBS-Win software, which is a part of the Vista Scan System was followed in this study to observe root resorption, widening of periodontal membrane, periapical radiolucency and evidence of progression or regression of carious lesion using the image processing software.

\section{Assessment of remineralization:}

Assessment of remineralization was done using measurement of radiodensity (\%). The radiodensity measurement was performed by drawing a line through the cavity, starting from cusp tip to cementoenamel junction (CEJ) (as a reference point). The measurement was taken at three points along the line (coronal, middle and apical). The average of the three readings was taken to represent the radiodensity at this area. This linear measurement was recorded in percent $(\%)$ for each selected tooth at base line "prior treatment" and at 18 months after treatment to determine the degree of remineralization that occurs with the three materials that used for restoration of selected teeth throughout the study.

\section{Assessment of microhardness}

The microhardness of dentin was measured using Vicker's microhardness tester (Mitutoyo MVK-HO Hardness testing machine, Akashi CO., Tokoyo, Japan). The diamond shaped identifications were carefully observed in an optical microscope. Two perpendicular diagonals were measured using fine micrometer that was attached with tester.
The average lengths of the two diagonals were used to calculate the microhardness value (VMH). All samples were subjected to the same conditions: $50 \mathrm{gm}$ load and 15 seconds dwell time. Then the collected numerical data were then registered, statistically analyzed, tabulated, and illustrated graphically.

\section{Statistical analysis}

The data obtained from in vivo study, were presented as frequencies (n) and percentages (\%). Chi-square $\left(x^{2}\right)$ test was used to compare between the three groups. Friedman's test was used to study the changes by time within each group. The significance level was set at $\mathrm{P} \leq 0.05$.

The data obtained from in vitro study were registered, tabulated and presented as mean, median, standard deviation (SD) and rang values. KruskalWallis test was used to compare between the three groups. Statistical analysis was performed with IBM ${ }^{\circledR}$ SPSS ${ }^{\circledR}$ Scientific Version 20 for windows.

\section{RESULTS}

\section{Clinical evaluation}

\section{Pain after treatment}

Through all time periods, no cases showed pain after treatment in the three groups.

\section{Tenderness to percussion}

Through all time periods, no cases showed tenderness to percussion in the three groups.

\section{Tooth mobility}

In comparison between tooth mobility in the three groups. After 18 months; 2 cases with tooth mobility appeared in glass ionomer (group 1) as well as Tooth Mousse groups (group 2) and 4 cases with tooth mobility in ozone group (group 3). But there was no statistically significant difference between the three groups.

\footnotetext{
* @ IBM Corporation, NY,USA. @ @SPSS, Inc., an IBM Company.
} 


\section{Tooth vitality}

In comparison between tooth vitality in the three groups. After 12 as well as 18 months; Ozone group showed non-vital teeth in 3 cases (20\%) while the other groups didn't show non-vital teeth. This difference was statistically significant.

\section{Radiographic evaluation}

\section{Internal resorption}

In comparison between internal resorption in the three groups. After 3 months, no cases showed internal resorption in the three groups. After 6, 9, 12 and 18 months; only one case $(6.7 \%)$ showed interal resorption in Ozone group, however there was no statistically significant difference between the three groups.

\section{Periodontal space ligament widening}

In comparison between the three groups, In Glass ionomer group (group1), there was a statistically significant increase in prevalence of periodontal space ligament widening after 6 months and 9 months. From 9 months to 18 months, no change was observed in the prevalence of periodontal ligament space widening.

In Tooth Mousse group (group2), there was a statistically significant increase in prevalence of periodontal space ligament widening after 6 months, 9 months and 18 months. From 12 months to 18 months, no change was observed in the prevalence of periodontal ligament space widening. In Ozone group (group3), there was a statistically significant increase in prevalence of periodontal space ligament widening as Tooth Mousse group (group2).

\section{Apical, lateral or furcal radiolucency}

Through all time periods, no cases showed apical, lateral or furcal radiolucency in the three groups.

\section{Assessment of remineralization by measure- ment of radiodensity\{\%\}.}

In comparison between the three groups in the measurement of radiodensity from baseline to 18 months, the greatest mean difference in radiodensity was noted in Tooth Mousse group (group 2), followed by Glass ionomer group (group 1), then Ozone group (group 3). However there was no statistically significant difference between the three groups from baseline to 18months (Table 1).

Bar chart representing mean difference in radiodensity from baseline to 18 months (Figure 1).

Table (1) Mean difference of radiodensity (\%) from baseline to 18 months and results of ANOVA test for the three groups.

\begin{tabular}{|c|c|c|c|}
\hline & Group 1 & Group 2 & Group 3 \\
\hline Range & -20.5 to 79.3 & -21.9 to 84 & -26.3 to 75 \\
\hline Mean & 28.107 & 42.720 & 14.480 \\
\hline Std Dev & 34.000 & 38.324 & 37.844 \\
\hline F & \multicolumn{3}{|c|}{2.341} \\
\hline $\begin{array}{c}\text { P value } \\
\text { (ANOVA test) }\end{array}$ & \multicolumn{3}{|c}{$109^{\text {ns }}$} \\
\hline
\end{tabular}

ns=not-significant at $p<0.005$

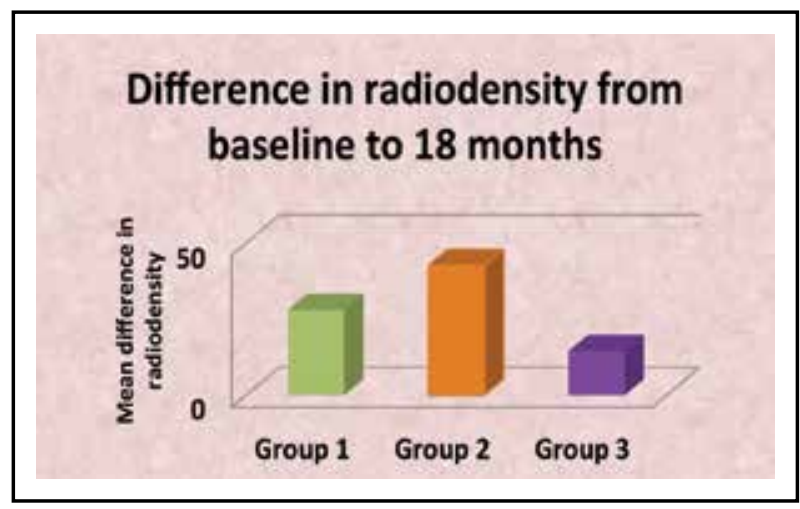

Fig. (1) Bar chart representing mean difference in radiodensity from baseline to after 18 months. 


\section{Microhardness assessment}

In comparison between the three groups in the assessment of microhardness. Ozone group showed higher mean (146.2MPa) followed with Tooth Mousse group (133.5MPa) then glass ionomer group (121.2MPa) but there was no statistically significant difference between the three groups (Table 2).

Bar chart representing mean microhardness of the three groups (figure 2).

Table (2) Mean \pm standard deviation (SD) values, median, range and results of Kruskal-Wallis test for comparison between micro-hardness of the three groups.

\begin{tabular}{|c|c|c|c|c|}
\hline $\begin{array}{c}\text { Micro- } \\
\text { hardness }\end{array}$ & $\begin{array}{c}\text { Ozone } \\
+ \text { GIC }\end{array}$ & $\begin{array}{c}\text { Glass } \\
\text { ionomer }\end{array}$ & $\begin{array}{c}\text { Tooth } \\
\text { Mousse } \\
+ \text { GIC }\end{array}$ & P-value \\
\hline $\begin{array}{c}\text { Mean } \pm \\
\text { SD }\end{array}$ & $146.2 \pm 46$ & $121.2 \pm 32.6$ & $133.5 \pm 39.5$ & 0.39 \\
Median & 136 & 131 & 138 & \\
Range & $83.7-238$ & $71.5-172$ & $69.7-184$ & \\
\hline
\end{tabular}

*: Significant at $P \leq 0.05$

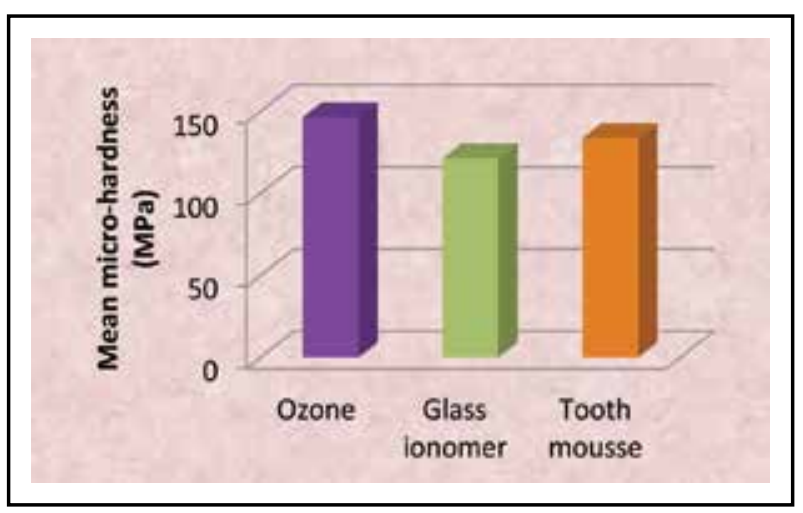

Fig. (2) Bar chart representing mean microhardness of the three groups

\section{DISCUSSION}

This study was conducted to evaluate the remineralizing capacity of glass ionomer cement, Casein Phosphopeptide Amorphous Calcium Phosphate (CPP-ACP) (Tooth Mousse) incorporated into glass ionomer cement and ozone on carious dentin of deciduous molars.

The dentin was chosen in this study because it demineralizes faster than enamel, and was more vulnerable to acid attack than enamel. Consequently, dentin showed early remineralization ${ }^{(7)}$.

The clinical results in ozone group (group3) at $12^{\text {th }}$ months follow up, 3 cases $(20 \%)$ lost their vitality while this didn't occur in the other two groups. At $18^{\text {th }}$ months follow up, two cases (13.3\%) in glass ionomer group (group1), as well as two cases (13.3\%) in Tooth Mousse group (group2) and 4 cases $(26.7 \%$ ) in ozone group (group3) reported mobility. This may be due to normal physiological root resorption.

The radiographic results for remineralizing effect of the three agents used, it was found that the clinical cases treated with Tooth Mousse mixed with glass ionomer cement (group 2) showed the greatest mean difference in radiodensity, followed by glass ionomer group(group 1), then ozone group (group 3). However there was no significant difference between the three groups.

These results were in accordance with Al Zraikat et al., 2011 ${ }^{(8)}$ and Patil et al., $2013{ }^{(9)}$. This could be related to the fact that CPP-ACP is electro neutral and can penetrate the subsurface lesion unaffected by the electric charge of enamel. Moreover the small size of the CPP-ACP nanocomplex can enter the porosities of an enamel subsurface lesion and diffuse along its concentration gradient into the body of the lesion.

And this is supported by Reynolds et al., 2008 ${ }^{(10)}$ who found that CPP-ACP tend to remineralize throughout the lesion even in presence of fluoride .This could be related to that casein phosphopeptide not only stabilizes amorphous calcium phosphate but also binds onto adsorbed macromolecules of biofilm on the tooth surface and serves as a reservoir for calcium and phosphate ions, buffering the ion activity of free calcium and phosphate. 
Thereby maintaining a state of super saturation with respect to enamel mineral, preventing enamel demineralization and promote remineralization.

However these results were not in agreement with Trairatvorakul et al., $2010{ }^{(11)}$, who found that the CPP-ACP was the least efficacious treatment in both preventing demineralization of the intact enamel specimens and in remineralizing the artificial carious specimens. This difference was attributed to the fact that their study was performed in the absence of an oral microbial environment or plaque accumulation on the tooth surfaces, which may have resulted in decreased CPP-ACP adherence to the tooth surfaces since CPP-ACP has been suggested to be incorporated into plaque by binding to bacterial cell surfaces and to intercellular plaque matrix.

In this study, ozone group (group1) showed the least mean difference in radiodensity. These results were in accordance with Polydorou et al., $2012{ }^{(12)}$. They evaluated the antimicrobial effect of ozone application on the most important cariogenic species. This could be related to failure of ozone gas to access the bacteria in "intact or decayed" tissue. This could be due to strong interactions of the gas with organic material in the superficial layers so that the diffusion within the tissue was greatly hampered.

However, these results were not in accordance with Atabek \& Oztas $2011{ }^{(13)}$ and Srinivasan et al., $2014{ }^{(14)}$. They investigated the antibacterial effect of ozone on cariogenic bacterial species. The difference could be due to the method of ozone application, most of the studies used ozone gas and so it can penetrate and reach to the full depth of the carious lesion and kill most of microorganisms within 10 seconds. In the present study, we used ozonized olive oil. This probably could be related to the fact that ozonized olive oil needs multiple applications to affect the remineralization. Another explanation could be that the presence of ozonized olive oil as pretreatment could have resulted a cavity not completely sealed with glass ionomer, and there was ingress of bacterial species which affected the remineralization.
The results of microhardness, in ozone group (group 3) showed higher mean followed by Tooth Mousse group (group 2) followed by group of glass ionomer cement( group 1).

These results were in accordance with Ogata et al., $2010{ }^{(15)}$ who found that CPP-ACP not only increases fluoride incorporation into plaque but also increases incorporation of fluoride into subsurface enamel lesion and substantially increases remineralization. This probably could be related to fluoride utilizes the calcium and phosphate in Tooth Mousse, thereby enhancing remineralization.

However, this is actually not surprising, since fluoride requires a good source of calcium and phosphate for remineralization of tooth enamel with the more acid resistant fluoroapatite, and CPP-ACP provides this in an amorphous soluble form.

Furthermore, these findings were in agreement with Shetty et al., $2014^{(16)}$ and Oliveira et al., $2015{ }^{(17)}$. That documented the synergistic effect of $\mathrm{CPP}-\mathrm{ACP}$ and fluoride in the remineralization of carious lesions. This may be because of the presence of fluoride in CPP-ACP make it more capable to remineralize the enamel, and there was another explanation that a combination of CPP$\mathrm{ACP}$ and fluoride resulted in localization of calcium and phosphate ions with fluoride ions forming CPPACFP nanocomplexes that are more acid-resistant.

On the other hand, the results of microhardness were not agreement with Lata et al., $2010{ }^{(18)}$ and Turssi et al., $2011^{(19)}$. It was observed that there was no remineralization at subsurface level and all the treatment groups failed to remineralize the subsurface lesion in depth. The reason could be; fluoride ions and CPP-ACP were not able to penetrate the subsurface enamel area, the in vitro set up does not exactly mimic the in vivo conditions occurring in the mouth, duration of the experimental set up ( seven days) is too short. The present study conducted on carious lesions and duration of the experimental set up (30 days) in artificial saliva. Moreover, the softened surface lesions remineralize faster and more completely than subsurface lesions. 


\section{CONCLUSION}

1. Casein phosphopeptide - Amorphous Calcium Phosphate (Tooth Mousse) mixed with Glass ionomer cement as well as glass ionomer alone seemed to be successful as a remineralizing agent in primary molars of 4-8 years old children.

2. All the remineralizing materials tested had similar effect on microhardness.

3. No correlation between clinical and in vitro study.

\section{REFERENCES}

1. Buzalaf MAR: Fuoride and the oral environment. Monogr. Oral Sci, Basel, Karger, 2011; 22: 97-114.

2. Fejerskow O, Kidd EA, Nyvad B and Baclum V: Defining the disease: an introduction in Fejerskow O, Kidd E (eds): Dental caries-The disease and its clinical management. Oxford, Blackwell Munksgaard, 2008, p3-6.

3. Larsen MJ and Pearce EI: Saturation of human saliva with respect to calcium salts. Arch Oral Biol 2003; 48(4):317-22.

4. Reynolds EC: Additional aids to remineralization of the tooth structure. In: Mount GJ, Hume WR, editors. Preservation and restoration of tooth structure. 2nded. Brisbane Australia: Knowledge Books and Software; 2005. P.111-8.

5. Bocci V: Scientific Medical aspects of ozone therapy. State of the art. Archives of Medical Research 2006; 37: 425-35.

6. Carvalho $\mathrm{CK}$ and Bezerra AC: Microbiological assessment of saliva from children subsequent to atraumatic restorative treatment (ART). Int. J Pediatric Dent 2003; $13: 186-92$.

7. Hara AT, Ando M, Gonzalez- Cabezas C, Cury JA, Serra MC and Zero DT: Protective effect of dental pellicle against erosive challenges in situ. J Dent Res.2006; 85(7):612-6.

8. Al-Zarikat H, Palamara JEA, Messer HH, Burrow MF and Reynolds EC: The incorporation of casein phosphopeptide - amorphous calcium phosphate into a glass ionomer. Dental Materials 2011; 27: 235-243.

9. Patil N, Choudhari S, Kulkarni S, and Joshi S R: Comparative evaluation of remineralizing potential of three agents on artificially demineralized human enamel: An in vitro study. J Conserv Dent. 2013 Mar-Apr; 16(2): 116-20.

10. Reynolds EC: Calcium phosphate - base remineralization system scientific evidence. Aust. Dent. J 2008 Sep; 35(3): 268-73.

11. Trairatvorakul C, Kangvansurakit $\mathrm{N}$ and Pathomburi J: In vitro comparison of self-versus professionally applied remineralizing materials. J Clin Pediatr Dent. 2010 summer; 34(4):323-8.

12. Polydorou O, Halili A, Wittmer A, Pelz K and Hahn P: The antibacterial effect of gas ozone after 2 months of in vitro evaluation. Clin Oral Investig. 2012 Apr; 16(2):545-50.

13. Atabek D and Oztas N: Effectiveness of ozone with or without the additional use of remineralizing solution on non-cavitated fissure carious lesions in permanent molars. Eur J Dent 2011; 5:393-9.

14. Srinivasan S, Prabhu V, Chandra S, Koshy S and Acharya $\mathrm{S}$ : Does ozone enhance the remineralizing potential of nanohydroxyapatite on artificially demineralized enamel? A laser induced fluorescence study, Proc. SPIE 8929 , Lasers in Dentistry XX, 892903 (February 18, 2014).

15. Ogata K, Warita S, Shimazu K, Kawakami T, Aoyagi $\mathrm{K}$, and Karibe H: effect of paste containing casein phosphopeptide-amorphous calcium phosphate and fluoride on enamel lesions: an in vitro $\mathrm{pH}$-cycling study. Pediatr Dent.2010 Sep-Oct; 32(5):433-8.

16. Shetty S, Hegde M N and Bopanna T: Enamel remineralization assessment after treatment with three different remineralizing agents using surface microhardness: an in vitro study. J Conserv Dent.2014 Jan - Feb; 17(1): 49-52.

17. Oliveira PR, Fonseca AB, Silva EM, Coutinho TC and Tostes MA: Remineralizing potential of CPP-ACP crèmes with and without fluoride in artificial enamel lesions. Aust Dent J. 2015 Jan 27.

18. Lata S, Varghese NO and Varughese JM: Remineralization potential of fluoride and amorphous calcium phosphatecasein phosphopeptide on enamel lesions; an in vitro comparative evaluation. J of Conservative Dentistry 2010; 13(1): 42-6.

19. Turssi CP, Maeda FA, Messias DC, Neto FC, Serra MC and Galafassi D : Effect of potential remineralizing agents on acid softened enamel. Am J Dent. 2011 Jun; 24(3):165-8. 